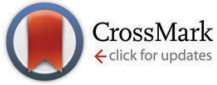

Cite this: New J. Chem., 2016, 40, 9007

Received (in Montpellier, France) 7th June 2016,

Accepted 9th September 2016

DOI: 10.1039/c6nj01785a

www.rsc.org/njc

\title{
The conjugate of jasmonic acid and tetrapeptide as a novel promising biologically active compound $\dagger$
}

\author{
Alicja Kapuscinska, Anna Olejnik* and Izabela Nowak
}

\begin{abstract}
A novel biologically active compound, the conjugate of jasmonic acid and tetrapeptide, has been obtained. The newly synthesized conjugate was characterized using MS, NMR and FTIR spectroscopy. The purity and melting point of the conjugate were determined using a differential scanning calorimetry technique. The safety of topical application of the conjugate was theoretically estimated. The obtained compound may exhibit the activity of jasmonic acid as well as that of tetrapeptide, therefore it is expected to have a promising effect on the skin.
\end{abstract}

Topical applications of ointments, gels and emulsions containing therapeutics have become very popular as non-invasive methods for the delivery of active substances to the skin. The cooperation of dermatologists and pharmacists has allowed the development of a formulation from which the release of active substances is most efficient. However, the search for new active substances or modification of the already existing therapeutics that may exhibit even better effects on the skin is continuing. Jasmonic acid and its derivatives, called also jasmonates, have been widely used in both the pharmaceutical and cosmetic industries. Jasmonic acid (JA) is a plant hormone that regulates plant response to abiotic and biotic stresses as well as plant growth and development. ${ }^{1}$ Dalko disclosed a composition of (dihydro-) jasmonic acid derivatives suitable for treating excessive sebum secretion. ${ }^{2}$ Jasmonates have also been suggested as active ingredients of a pharmaceutical composition for stimulating epidermal renewal and smoothing skin texture. ${ }^{3}$ Jasmonates may also be used as depigmenting agents. ${ }^{4}$ It is believed that they may be used to stimulate the growth of human keratin fibres, to inhibit hair loss; therefore these compounds may be used, e.g., in therapy of different types of alopecia. ${ }^{5}$ Moreover, local administration of

Faculty of Chemistry, Adam Mickiewicz University in Poznań, Umultowska 89b, 61-614 Poznań, Poland. E-mail: annamar@amu.edu.pl; Tel: +48 618291580 $\dagger$ Electronic supplementary information (ESI) available: ${ }^{1} \mathrm{H}$ NMR and ${ }^{13} \mathrm{C}$ NMR spectra of the JA-YPFF- $\mathrm{NH}_{2}$ conjugate, HR-MS spectrum, CD spectrum and the results of Toxtree estimation of the properties of JA-YPFF-NH $\mathrm{NH}_{2}$. See DOI: 10.1039/ c6nj01785a methyl jasmonate gave good results for the treatment of lichen planus and lentigomaligna of the face with mixed basal spinal cell carcinoma treatment. ${ }^{6}$ Jasmonates are also supposed to inhibit in vitro cell proliferation and to induce cell death in melanoma skin cancer. ${ }^{7}$ In vitro studies on the Episkin ${ }^{\mathrm{TM}}$ model proved that sodium tetrahydrojasmonate stimulates an increase in the amount of Ki67 (a nuclear protein that may be crucial for cellular proliferation processes) in the basal layer of the epidermis. ${ }^{8,9}$ Tran et al. have proposed the use of sodium tetrahydrojasmonate to exfoliate the skin and reduce visible signs of skin aging. ${ }^{10}$ In vivo studies have shown that LR2412 reversed steroid-induced atrophy of the skin and improved the deposition of fibrillin-rich microfibrils in the papillary dermis. According to the in vitro release studies of an LR2412 solution using a Franz diffusion cell on excised human skin, after $24 \mathrm{~h}$ of study, a total of circa $6 \%$ of the applied dose was released to the skin. This result has stimulated the search for a derivative of jasmonic acid that would show a higher percentage of release in in vitro release studies and hence show greater bioavailability than commercial sodium tetrahydrojasmonate. ${ }^{10}$ Other innovative active ingredients that have been widely used in pharmaceutical and skincare products are bioactive peptides such as Tyr-ProPhe-Phe- $\mathrm{NH}_{2}$ (YPFF). This tetrapeptide is an agonist of opioid receptors and reduces neurogenic hyperreactivity associated with the release of the neuropeptide CGRP (calcitonin gene related peptide). ${ }^{11}$ As a commercial product, Skinasensyl ${ }^{\mathbb{R}}$ is a synthetic acetylated YPFF tetrapeptide (AcYPFF), which when applied to the skin weakens the stimulation of nerve endings. This results in a reduction in hypersensitivity of the skin. ${ }^{12-14}$ Jasmonic acid has been shown to occur in the conjugated form with a variety of amino acids (i.e. leucine, isoleucine and valine) in higher plants such as barley leaf tissue and arbuscular mycorrhizal barley roots. ${ }^{15}$ This finding prompted us to synthesize the conjugate of jasmonic acid and tetrapeptide. As mentioned above, both of these compounds provide beneficial effects on the skin, therefore we suggest that the newly obtained conjugate may be a promising active ingredient for topical applications. The aim of 

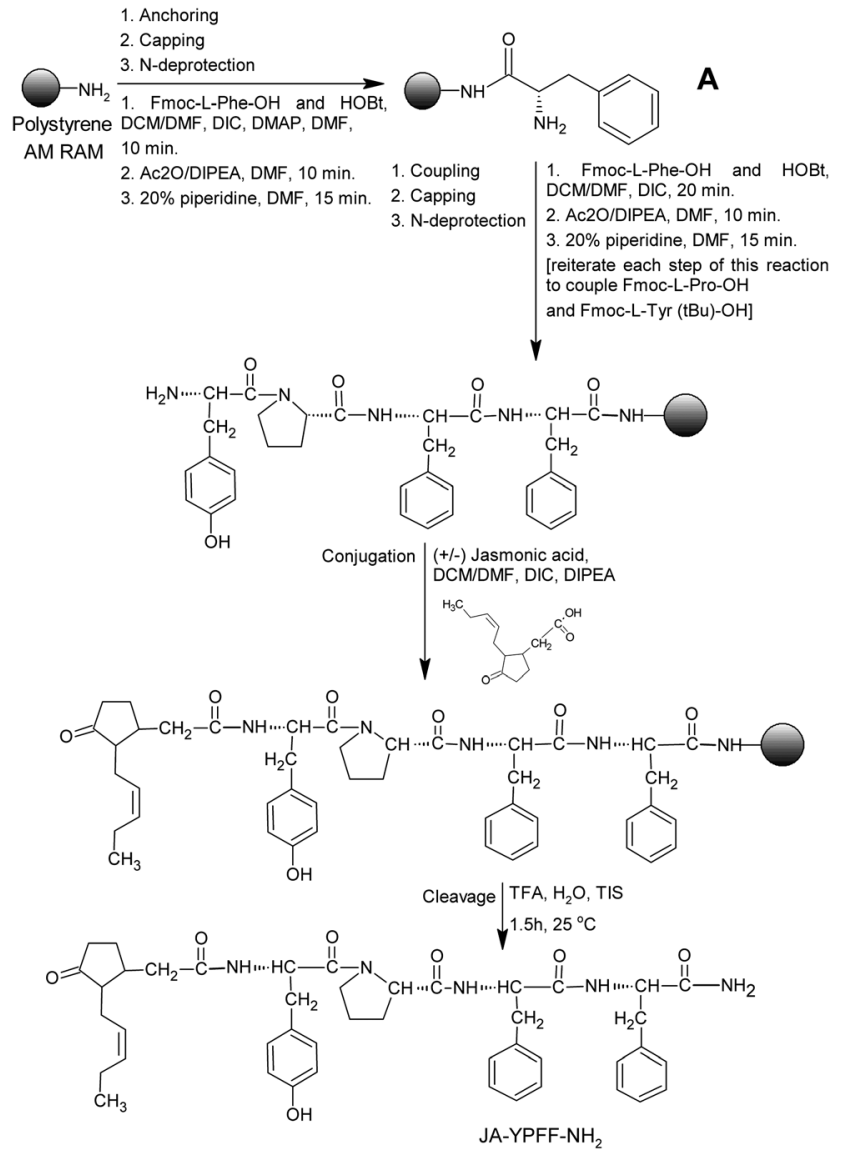

Fig. 1 Synthesis of the JA-YPFF- $\mathrm{NH}_{2}$ conjugate.

this study was to develop and characterise a new biologically active compound that is the conjugate of jasmonic acid and tetrapeptide (JA-YPFF- $\mathrm{NH}_{2}$ ), which may exhibit the activity of jasmonic acid as well as that of the YPFF peptide.

The synthesis of the JA-YPFF- $\mathrm{NH}_{2}$ conjugate performed by LipoPharm.pl is presented in Fig. 1. The peptide YPFF- $\mathrm{NH}_{2}$ was synthesized manually on the 0.3 millimole scale via a solid-phase method using AM RAM resin and the Fmoc/But procedure. ${ }^{16}$ The racemic jasmonic acid was purchased from TCI Europe N.V. and the amino-acid derivatives (Fmoc-L-Phe-OH, Fmoc-L-Pro-OH, and Fmoc-L-Tyr $(t \mathrm{Bu})-\mathrm{OH})$ were purchased from Sigma-Aldrich. The precise amounts of amino acid derivatives and jasmonic acid used in the conjugate synthesis were as follows: $585.1 \mathrm{mg}$ of Fmoc-L-Phe-OH, $506.1 \mathrm{mg}$ of Fmoc-L-Pro-OH, $689.3 \mathrm{mg}$ of Fmoc-L-Tyr $(t \mathrm{Bu})-\mathrm{OH}$ and $371.1 \mathrm{mg}$ of jasmonic acid. Before the synthesis, the AM RAM resin was treated with a DCM/DMF solution ( $\mathrm{v} / \mathrm{v}, 9: 1)$ for $1 \mathrm{~h}$. After that the solvents were filtered. The synthesis of the conjugate began by adding to the AM RAM resin a mixture of HOBt and Fmoc-L-Phe-OH, previously dissolved in DCM/DMF (v/v, 9:1). The Fmoc-L-Phe$\mathrm{OH}$ unit, which represents the C-terminus, was anchored to the rink amide resin by using DIC and DMAP in DMF. After capping $\left(\mathrm{Ac}_{2} \mathrm{O} / \mathrm{DIPEA}\right.$ in DMF), to protect unreacted hydroxyl groups of the resin, the Fmoc group was deprotected using a $20 \%$ solution of piperidine in DMF, then amide A was obtained. ${ }^{17}$
The addition of Fmoc-L-Phe-OH, Fmoc-L-Pro-OH, Fmoc-L$\operatorname{Tyr}(t \mathrm{Bu})-\mathrm{OH}$ and jasmonic acid to A was performed using DIC as a coupling agent in the presence of HOBt. The capping was carried out using $\mathrm{Ac}_{2} \mathrm{O} /$ DIPEA in DMF and the N-Fmoc deprotection was performed using a $20 \%$ solution of piperidine in DMF. After each deprotection of the amino group, a chloranil test was performed to detect the amino groups. The result of the test was positive; dark blue to green beads of the resin implied that there were free amino groups and the deprotection was performed successfully. After careful washing of the resin, the JA-YPFF- $\mathrm{NH}_{2}$ conjugate was contemporarily cleaved from the resin, via acidic treatment using a mixture of TFA: $\mathrm{H}_{2} \mathrm{O}$ :TIS (v/v, 92.5:2.5:5) for 1.5 hour at $25{ }^{\circ} \mathrm{C} .{ }^{18}$ Fig. 1 presents the general synthesis scheme of the conjugate and does not include the stereoisomeric structures of jasmonic acid. However, there are two chiral centers at C-3 and C-4 and therefore four possible stereoisomeric forms of JA, $(3 S, 4 S)$-JA or $(+)-\mathrm{JA},(3 R, 4 R)-\mathrm{JA}$ or $(-)-\mathrm{JA},(3 S, 4 R)-\mathrm{JA}$, known as $(-)-$-epi-JA, and $(+)-(3 R, 4 S)$-JA, known as $(+)$-epi-JA, that may be generated. It was investigated that commercially available jasmonic acid is a racemic mixture containing approximately $3-5 \%$ each of (+)-epi-JA and (-)-epi$\mathrm{JA}$, and $45-47 \%$ each of (+)-JA and (-)-JA. ${ }^{19}$ No pure JA stereoisomers have been commercially available so far. Therefore it can be concluded that the obtained product is in the majority a mixture of (+)-JA and (-)-JA conjugates. Both forms are biologically active, however (-)-JA is believed to be the more biologically active compound. ${ }^{1}$

The desired product was purified using RP-HPLC. In this process a Phenomenex Luna column $(5 \mu \mathrm{m}, \mathrm{C} 18(2), 100 \AA$, $10 \times 250 \mathrm{~mm}$ ) was employed. As a mobile phase water and a mixture of acetonitrile and $0.1 \%$ of TFA were used in the gradient elution. The purity of the obtained conjugate was $>97 \%$. The conjugate of jasmonic acid and tetrapeptide YPFF- $\mathrm{NH}_{2}$ is a white powder with poor solubility in water, but a high solubility in organic solvents such as methanol and ethanol.

To confirm the molecular weight of the conjugate, the mass spectra were recorded using a hybrid QTOF instrument (AB Sciex, model $5600^{+}$). Ions were generated using electrospray ionization

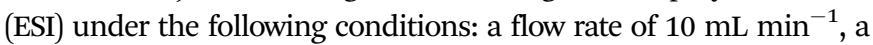
dry gas flow of $8 \mathrm{~L} \mathrm{~min}^{-1}$, a nebulizer pressure of $1.5 \mathrm{bar}$, a spray voltage of $5500 \mathrm{~V}$, and a drying gas temperature of $250{ }^{\circ} \mathrm{C}$. Analyst 1.6TF software (AB Sciex) was used to process the raw spectra. The MS spectrum was obtained in the positive mode. The conjugate of JA and tetrapeptide was successfully identified using mass spectrometry. The positive ion mode presents a peak of a protonated molecular ion $[\mathrm{M}+\mathrm{H}]^{+}$at $m / z$ 765.39. Additionally, a molecular ion with associated sodium $[\mathrm{M}+\mathrm{Na}]^{+}$at $m / z 787.37$ was detected (Fig. 2).

Fourier-transform infrared spectroscopy was carried out using a Nicolet FTIR 200 spectrophotometer (Thermo Fisher Scientific, Inc., USA). The spectrum was collected in the wavelength range of $500-4000 \mathrm{~cm}^{-1}$. The typical chemical bonds of the synthesized compound were successfully characterized. FTIR measurements of JA-YPFF- $\mathrm{NH}_{2}$ and the identified functional groups are presented in Fig. 3. The band at about $3302 \mathrm{~cm}^{-1}$ corresponds to $\mathrm{O}-\mathrm{H}$ stretching vibrations of the $\mathrm{OH}$ group. The band at about $3028 \mathrm{~cm}^{-1}$ is assigned to $=\mathrm{C}-\mathrm{H}$ 


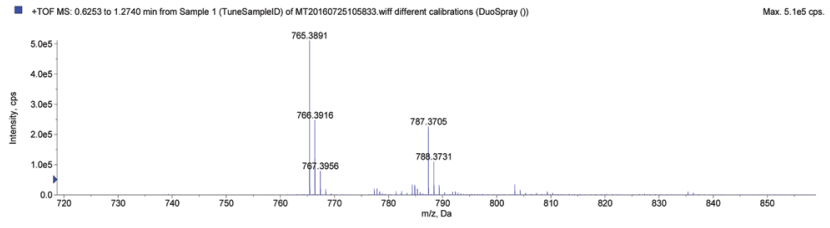

Fig. 2 MS spectrum of the JA-YPFF-NH .

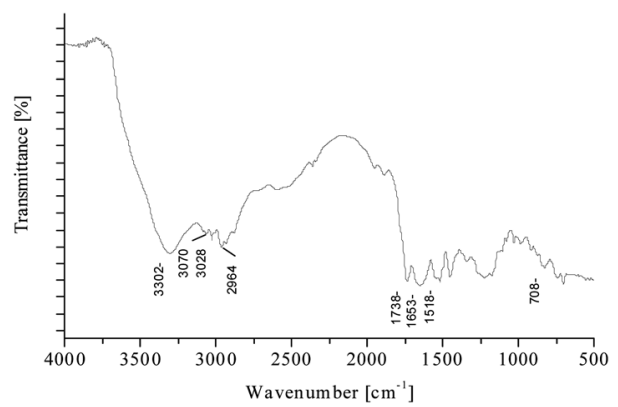

Fig. 3 FTIR spectrum of the JA-YPFF-NH $\mathrm{N}_{2}$ conjugate.

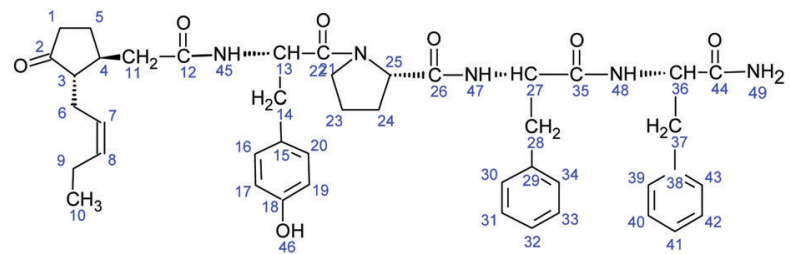

(-)-JA-YPFF- $\mathrm{NH}_{2}$

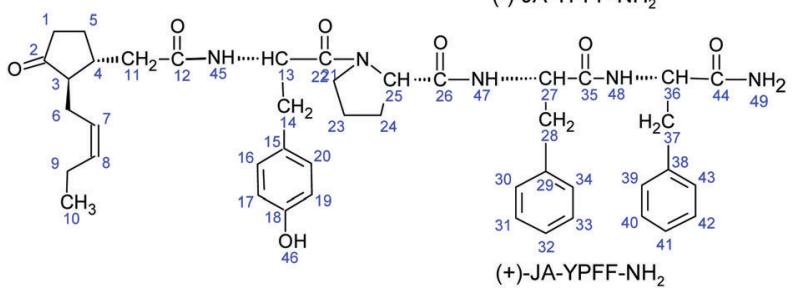

Fig. 4 The structure of (-)- and (+)-JA-YPFF-NH $\mathrm{NH}_{2}$ with numbered atoms.

stretching vibrations. Moreover, at $2964 \mathrm{~cm}^{-1}$ the stretching vibrations of $\mathrm{C}-\mathrm{H}$ were identified. The $\mathrm{C}=\mathrm{O}$ group was manifested as a single band at about $1738 \mathrm{~cm}^{-1}$ region, whereas the amine group was identified at about $1653 \mathrm{~cm}^{-1}$ (C-N, stretch) and $3070 \mathrm{~cm}^{-1}$. The $\mathrm{C}-\mathrm{H}$ and $\mathrm{C}=\mathrm{C}$ bonds from the aromatic ring gave the bands at $2964 \mathrm{~cm}^{-1}$ and $1518 \mathrm{~cm}^{-1}$, respectively.

To confirm the structure of JA-YPFF- $\mathrm{NH}_{2}$, its nuclear magnetic resonance (NMR) spectra were recorded using a NMR spectrometer (Bruker Avance $600 \mathrm{MHz}$; Bruker, UK). The conjugate sample was dissolved in chloroform-d (Sigma-Aldrich). The numbering of the atoms in the structure scheme (Fig. 4) was produced in order to present the NMR spectroscopy results. The ${ }^{1} \mathrm{H}$ NMR shift for $\mathrm{CDCl}_{3}$ is $7.24 \mathrm{ppm}$ and its ${ }^{13} \mathrm{C}$ NMR shift is $77.0 \mathrm{ppm}$.

\section{Stereoisomer 1}

${ }^{1} \mathrm{H}$ NMR $\left(\mathrm{CDCl}_{3}, 600 \mathrm{MHz}\right): \delta \mathrm{H} 0.90(3 \mathrm{H}, \mathrm{t}, \mathrm{H}-10), 1.29(2 \mathrm{H}, \mathrm{m}, \mathrm{H}-5)$, 1.62 (2H,br, H-23), 1.70-1.78 (1H, m, H-3), 1.85 (2H, br, H-24), 1.98
(2H, quint, H-9), 2.01-2.06 (2H, m, H-11), 2.24 (2H, br, H-6), 2.27 (1H, br, H-4), 2.32 (2H, br, H-5), 2.47 (2H, br, H-1), 2.89 (2H, br, H-28), 2.96 (2H, br, H-37), 3.19 (2H, br, H-14), 3.67 (2H, br, H-22), 4.37 (1H, br, H-25), 4.70 (1H, br, H-27), 4.78 (1H, br, H-36), 4.88 (1H, br, H-13), 5.14-5.20 (1H, m, H-7), 5.33-5.48 (1H, m, H-8), 6.61-6.83 (2H, m, H-16, H-20), 6.94 (2H, br, H-17,H-19), 7.03-7.26 (10H, m, H-30-H-34 and H-39-H-43), $7.31(1 \mathrm{H}, \mathrm{s}, \mathrm{H}-45), 7.53(1 \mathrm{H}, \mathrm{s}$, $\mathrm{H}-48)$, 7.93 (1H, s, H47).

${ }^{13} \mathrm{C} \mathrm{NMR}\left(\mathrm{CDCl}_{3}, 600 \mathrm{MHz}\right): \delta \mathrm{C} 14.06(\mathrm{C}-10), 20.52(\mathrm{C}-9)$, 24.55 (C-23), 25.36 (C-6), 26.60 (C-5), 28.55 (C-24), 37.15 (C-14), 37.57 (C-11), 38.16 (C-37), 38.29 (C-28), 38.82 (C-4), 40.2 (C-11), 40.50 (C-1), 47.66 (C-22), 52.29 (C-13), 53.98 (C-36), 53.76 (C-3), 54.55 (C-27), 60.55 (C-25), 115.7 (C-17, C-19), 124.79 (C-7), 125.72-129.15 (C-30-C-34, C-39-C-43), 129.37 (C-15), 130.50 (C-16, C-20), 134.02 (C-8), 135.85 (C-29, C-37), 155.81 (C-18), 171.22 (C-26), 171.58 (C-35), 172.01 (C-21), 172.12 (C-44), 173.39 (C-12), 220.30 (C-2).

\section{Stereoisomer 2}

${ }^{1} \mathrm{H}$ NMR ( $\left.\mathrm{CDCl}_{3}, 600 \mathrm{MHz}\right): \delta \mathrm{H} 0.86(3 \mathrm{H}, \mathrm{t}, \mathrm{H}-10), 1.29(2 \mathrm{H}, \mathrm{m}$, $\mathrm{H}-5), 1.62$ (2H, br, H-23), 1.70-1.78 (1H, m, H-3), 1.85 (2H, br, $\mathrm{H}-24), 1.98$ (2H, quint, H-9), 2.01-2.06 (2H, m, H-11), $2.24(2 \mathrm{H}$, br, H-6), 2.27 (1H, br, H-4), 2.32 (2H, br, H-5), 2.47 (2H, br, H-1), 2.89 (2H, br, H-28), 2.96 (2H, br, H-37), 3.19 (2H, br, H-14), 3.52 (2H, br, H-22), 4.37 (1H, br, H-25), 4.70 (1H, br, H-27), 4.78 (1H, br, H-36), 4.88 (1H, br, H-13), 5.23-5.30 (1H, m, H-7), 5.335.48 (1H, m, H-8), 6.61-6.83 (2H, m, H-16, H-20), 6.94 (2H, br, $\mathrm{H}-17, \mathrm{H}-19), 7.03-7.26$ (10H, m, H-30-H-34 and $\mathrm{H}-39-\mathrm{H}-43), 7.31$ (1H, s, H-45), 7.53 (1H, s, H-48), 7.93 (1H, s, H47).

${ }^{13} \mathrm{C}$ NMR $\left(\mathrm{CDCl}_{3}, 600 \mathrm{MHz}\right): \delta \mathrm{C} 14.13(\mathrm{C}-10), 20.52(\mathrm{C}-9)$, 24.57 (C-23), 25.39 (C-6), 26.76 (C-5), 28.55 (C-24), 37.26 (C-14), 37.66 (C-11), 38.16 (C-37), 38.29 (C-28), 38.82 (C-4), 40.2 (C-11), 40.60 (C-1), 46.83 (C-22), 52.34 (C-13), 54.08 (C-36), 53.66 (C-3), 54.60 (C-27), 60.55 (C-25), 115.95 (C-17, C-19), 124.94 (C-7) 125.72-129.15 (C-30-C-34, C-39-C-43), 129.41 (C-15), 130.38 (C-16, C-20), 134.09 (C-8), 136.18 (C-29, C-37), 156.28(C-18), 171.22 (C-26), 171.58 (C-35), 172.01 (C-21), 172.12 (C-44), 173.52 (C-12), 220.1 (C-2).

The melting point of the conjugate crystals was determined using differential scanning calorimetry (DSC) using a differential scanning calorimeter (Q2000; TA Instruments, USA). The conjugate sample was weighted on an aluminium pan which was then hermetically closed and placed into a DSC analyser. The initial and final temperatures of the measurement were 0 and $100{ }^{\circ} \mathrm{C}$, respectively, and the temperature ramp was $5{ }^{\circ} \mathrm{C} \mathrm{min}^{-1}$. The results of the DSC study are plotted with the percentage heat flow on the $Y$-axis and temperature on the $X$-axis. The DSC device is designed to maintain the test sample and the reference sample at the same temperature when they are heated. The precise and high quality data obtained from DSC provide information on the thermal stability of the samples in process development and in the formulation of potential therapeutics. Moreover, the knowledge of the melting point of the active compounds is essential in order to select the temperature for 


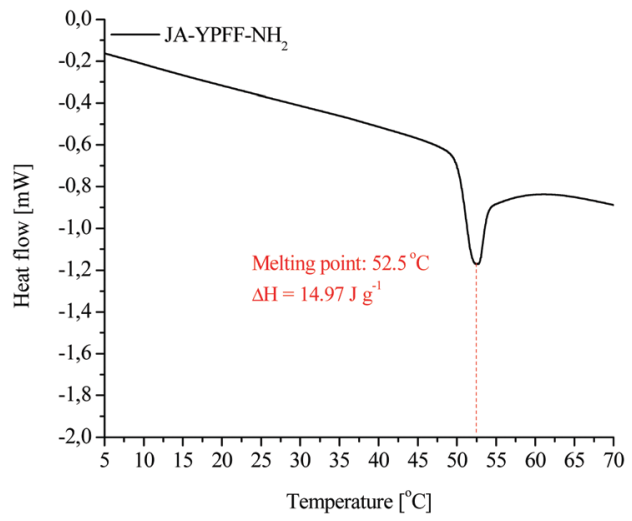

Fig. 5 The DSC curve of the JA-YPFF-NH $\mathrm{N}_{2}$ conjugate.

storage as well as the temperature for preparation of either the pharmaceutical or cosmetic formulations containing these compounds. The melting point of the conjugate was established using differential scanning calorimetry to be $52.42{ }^{\circ} \mathrm{C}$. The change in enthalpy $(\Delta H)$ of the melting process of the conjugate crystals was determined. In order to determine $\Delta H$, a line tangent to the DSC curve was drawn and the surface area of the peak was calculated. The change in melting enthalpy of the conjugate was $14.97 \mathrm{~J} \mathrm{~g}^{-1}$. The single peak in the DSC curve proves that the compound obtained does not contain any contaminations and that the purification method performed after the conjugate synthesis was effective. The DSC curve of JA-YPFF- $\mathrm{NH}_{2}$ is presented in Fig. 5.

The potential toxic hazard of JA-YPFF- $\mathrm{NH}_{2}$ was estimated using the application Toxtree. This application makes structurebased predictions for a number of toxicological endpoints. The conjugate is intended for topical applications. Therefore, it is important to investigate whether this substance may cause skin irritation before performing in vivo studies on volunteers. Toxtree analysis is based on the Threshold of Toxicological Concern (TTC) concept designed to establish a safety level of exposure to chemical compounds. ${ }^{20}$ The most popular approach for structuring chemicals in order to make a TTC estimation is the Cramer classification tree. ${ }^{21}$ The Toxtree software was evolved to implement diverse rule-based estimation approaches and was commissioned by the European Chemicals Bureau (ECB). ${ }^{22}$

Prior to in vitro and in vivo studies the potential risk of topical application of the conjugate was theoretically assessed. In order to estimate the potential toxic hazard of JA-YPFF- $\mathrm{NH}_{2}$, the open source application Toxtree was used. The results of this estimation show that the conjugate of jasmonic acid and tetrapeptide does not include skin sensitization reactivity domains and is not corrosive to the skin. Moreover, this estimation gave a negative response to both genotoxic and nongenotoxic carcinogenicity of the conjugate. Therefore, it can be concluded that JA-YPFF- $\mathrm{NH}_{2}$ may be used in topical applications and should cause no damage to skin appearance, condition and health. Therefore, it may be a promising active ingredient to add to topical formulations.

Since the conjugate is not highly soluble in water, we suggest that ethanol could be used as a solvent for the topical use of the active compound. This solvent is widely used in topical applications in cosmetology, dermatology and pharmacy. The excessive use of ethanolic solutions on the skin may cause dryness. Therefore, we suggest using a small amount of ethanol to dissolve the conjugate (e.g. $200 \mu \mathrm{l}$ of EtOH per $5 \mathrm{mg}$ of JA-YPFF- $\mathrm{NH}_{2}$ ) and to mix the obtained ethanolic solution of the conjugate with other components of pharmaceutical formulations. Moreover, ethanol is a well known skin penetration enhancer. ${ }^{23,24}$ Furthermore, the conjugate could also be encapsulated into nanocarriers or mixed with an oily phase of the pharmaceutical formulation, as long as the temperature during the preparation process does not exceed $35-40{ }^{\circ} \mathrm{C}$ (a higher temperature may cause the risk of conjugate degradation). Characterization of the newly obtained conjugate $\mathrm{JA}-\mathrm{YPFF}-\mathrm{NH}_{2}$ was carried out successfully. The theoretical mass of the obtained compound was confirmed using MS spectrometry. The structure of JA-YPFF- $\mathrm{NH}_{2}$ was confirmed using NMR spectroscopy and the typical chemical bonds of the conjugate were effectively characterized using FTIR spectroscopy. Moreover, the purity and melting point of the conjugate were determined using a DSC technique. Furthermore, the safety of topical application of the conjugate was theoretically estimated. It has also been shown that the obtained compound is not corrosive to skin and does not cause genotoxic and nongenotoxic carcinogenicity. Additionally, it is a promising compound that may exhibit a beneficial effect on the skin. The effect of this compound on the skin will be further studied in in vitro and in vivo tests.

\section{Conflict of interest}

The authors declare no conflict of interest.

\section{Acknowledgements}

Financial support from the Polish Ministry of Science and Higher Education is acknowledged. The authors would like to express their gratitude to Dr. Marta Krysmann (University of Central Lancashire, UK) for the support and cooperation with DSC studies. The authors also would like to thank Dr. Tomasz Pędziński (Adam Mickiewicz University in Poznan, Poland) for the support with the MS studies.

\section{Referencesand notes}

1 R. A. Creelman and J. E. Mullet, Annu. Rev. Plant Biol., 1997, 48, 355.

2 M. Dalko, Patent WO 2011001111 A3, 2010.

3 C. Boulle, M. Dalko, J. L. Leveque and L. Simonetti, Patent US 8603502 B2, 2013.

4 S. Allemand, M. Devie and F. Levy, Patent US 2014/0050679 A1, 2014.

5 T. A. Dar, M. Uddin, M. M. A. Khan, K. Hakeem and H. Jaleel, Environ. Exp. Bot., 2015, 115, 49.

6 B. Palmieri, T. Iannitti, S. Capone and E. Flescher, Eur. Rev. Med. Pharmacol. Sci., 2011, 15, 333. 
7 I. M. Cesari, E. Carvalho, M. Figueiredo Rodrigues, B. D. S. Mendonça, N. D. Amôedo and F. D. Rumjanek, Int. J. Cell Biol., 2014, 2014, 1.

8 J. F. Michelet, C. Olive, E. Rieux, D. Fagot, L. Simonetti, J. B. Galey, M. Dalko-Csiba, B. A. Bernard and R. Pereira, Exp. Dermatol., 2012, 21, 398.

9 J. Bullwinkel, B. Baron-Lühr, A. Lüdemann, C. Wohlenberg, J. Gerdes and T. Scholzen, J. Cell. Physiol., 2006, 206, 624.

10 C. Tran, J. F. Michelet, L. Simonetti, F. Fiat, A. Garrigues, A. Potter, E. Segot, R. E. Watson, E. E. Griffiths and O. De Lacharriere, J. Eur. Acad. Dermatol. Venereol., 2014, 28, 415. 11 N. Boulais and L. Misery, Eur. J. Dermatol., 2008, 8, 119.

12 G. Pauly, P. Moussou, J. L. Contet-Audonneau, L. Danoux, O. Freis, M. Sabadotto, I. Benoit, A. Misery and A. Rathjens, Int. J. Cosmet. Sci., 2009, 31, 480.

13 G. Pauly, O. Freis, A. Rathjens, L. Danoux, I. Benoit, J. L. Contet-Audonneau and P. Moussou, IFSCC Mag., 2009, 12, 25.

14 R. Jourdain, P. Bastien, D. Lacharrie'Re and G. Rubinstenn, Int. J. Cosmet. Sci., 2005, 27, 353.
15 R. Kramell, O. Miersch, B. Hause, B. Ortel, B. Parthier and C. Wasternack, FEBS Lett., 1997, 414(2), 197.

16 A. S. Culf and R. J. Ouellette, Molecules, 2010, 15(8), 5282.

17 A. Guaragna, G. N. Roviello, S. D’Errico, C. Paolella, G. Palumbo and D. D'Alonzo, Tetrahedron Lett., 2015, 56(6), 775.

18 G. N. Roviello, S. Di Gaetano, D. Capasso, S. Franco, C. Crescenzo, E. M. Bucci and C. Pedone, J. Med. Chem., 2011, 54(7), 2095.

19 L. Holbrook, P. Tung, K. Ward, D. M. Reid, S. Abrams, N. Lamb, J. W. Quail and M. M. Moloney, Plant Physiol., 1997, 114, 419.

20 G. Patlewicz, N. Jeliazkova, R. J. Safford, A. P. Worth and B. Aleksiev, SAR QSAR Environ. Res., 2008, 19(5-6), 495.

21 H. Kalkhof, M. Herzler, R. Stahlmann and U. Gundert-Remy, Arch. Toxicol., 2012, 86(1), 17.

22 R. Safford, Regul. Toxicol. Pharmacol., 2008, 51(2), 195.

23 A. C. Williams and B. W. Barry, Adv. Drug Delivery Rev., 2004, 56(5), 603.

24 M. E. Lane, Int. J. Pharm., 2013, 447(1-2), 12. 